\title{
Trends
}

\section{Assessment of changes in nicotine dependence, motivation, and symptoms of anxiety and depression among smokers in the initial process of smoking reduction or cessation: a short-term follow-up study}

\author{
Avaliação de mudanças na dependência da nicotina, motivação \\ e sintomas de ansiedade e depressão em fumantes no processo inicial de \\ redução ou cessação do tabagismo: estudo de seguimento de curto prazo
}

Luciana Rizzieri Figueiró, ${ }^{1}$ Cassandra Borges Bortolon, ${ }^{1}$ Mariana Canellas Benchaya, ${ }^{1}$ Nadia Krubskaya Bisch, ${ }^{1}$ Maristela Ferigolo, ${ }^{1}$ Helena Maria Tannhauser Barros, ${ }^{1}$ Denise Conceição Mesquita Dantas ${ }^{2}$

\begin{abstract}
Introduction: The first days of a quit attempt represent an important challenge to long-term abstinence, especially because of the changes that take place over this period.

Objective: To examine whether smokers who have recently changed their smoking behavior show changes in the intensity of nicotine dependence, motivational stage, or symptoms of anxiety and depression relative to smokers without recent changes in smoking behavior.

Methods: Smokers attending a support group for smoking cessation in Porto Alegre, southern Brazil, were invited to participate. The program consisted of four weekly sessions. Smokers answered questionnaires covering intensity of nicotine dependence, stage of motivation, and symptoms of anxiety and depression at baseline and in the fourth week. Urine was collected at both time points, tested for cotinine concentration, and used to determine the final status of smokers.

Results: Of the 54 smokers included in the study, 20 (37\%) stopped smoking or decreased tobacco use. Both smokers who stopped or reduced tobacco use and those who did not change their behavior presented a decrease in nicotine dependence scores $(p=0.001)$. Conversely, only the smokers who changed behavior presented an increase in scores in the maintenance stage $(p<0.001)$.

Conclusion: When modifying tobacco use, smokers face a difficult process, marked by several changes. A better understanding of these changes and their implications for treatment are discussed. Keywords: Smoking cessation, tobacco use disorder, motivation, anxiety, depression.
\end{abstract}

\section{Resumo}

Introdução: Os primeiros dias de uma tentativa de parar de fumar representam um desafio importante para a abstinência a longo prazo, especialmente por causa das mudanças que ocorrem nesse período.

Objetivo: Examinar se fumantes que mudaram recentemente seu hábito de fumar mostram mudanças na intensidade da dependência à nicotina, no estágio motivacional ou nos sintomas de ansiedade e depressão em comparação com fumantes sem mudanças recentes em seu hábito de fumar.

Métodos: Fumantes participando de um grupo de apoio para a cessação do tabagismo em Porto Alegre, sul do Brasil, foram convidados a participar do estudo. O programa consistia de quatro sessões semanais. Os fumantes responderam a questionários que avaliaram a intensidade da dependência à nicotina, o estágio motivacional e sintomas de ansiedade e depressão no início do programa e na $4^{a}$ semana. Amostras de urina foram coletadas nos dois momentos para avaliar a concentração de cotinina para determinar o status final dos fumantes.

Resultados: Dos 54 fumantes incluídos no estudo, 20 (37\%) pararam de fumar ou reduziram o uso de tabaco. Tanto os fumantes que pararam ou reduziram o uso de tabaco quanto aqueles que não mudaram seu hábito apresentaram diminuição nos escores de dependência à nicotina $(p=0,001)$. Por outro lado, apenas os fumantes que mudaram seu hábito apresentaram aumento nos escores do estágio de manutenção $(p<0,001)$.

Conclusão: Ao modificar o uso de tabaco, os fumantes enfrentam um processo difícil, marcado por várias mudanças. Um meIhor entendimento dessas mudanças e suas implicações para o tratamento são discutidas.

Descritores: Abandono do hábito de fumar, transtorno por uso de tabaco, motivação, ansiedade, depressão.

\footnotetext{
${ }^{1}$ VIVAVOZ Call Center, Universidade Federal de Ciências da Saúde de Porto Alegre (UFCSPA), Porto Alegre, RS, Brazil. ${ }^{2}$ UFCSPA, Porto Alegre, RS, Brazil. Financial support: Secretaria Nacional de Políticas sobre Drogas (SENAD) and Associação Mário Tannhauser de Ensino, Pesquisa e Assistência (AMTEPA). HMTB receives a 1C Research Productivity Grant from Conselho Nacional de Desenvolvimento Científico e Tecnológico (CNPq).

Submitted Nov 06 2012, accepted for publication Feb 25 2013. No conflicts of interest declared concerning the publication of this article.

Suggested citation: Figueiró LR, Bortolon CB, Benchaya MC, Bisch NK, Ferigolo M, Barros HM, et al. Assessment of changes in nicotine dependence, motivation, and symptoms of anxiety and depression among smokers in the initial process of smoking reduction or cessation: a short-term follow-up study. Trends Psychiatry Psychother. 2013;35(3):212-20.
} 


\section{Introduction}

Tobacco smoking is the leading cause of preventable death worldwide, whereas quitting smoking is an effective way to prevent many diseases and premature mortality. ${ }^{1}$ An increasingly large body of information about the harms of smoking and a greater availability of treatment programs has led to a growing effort among smokers to quit, however more than $95 \%$ of smoking cessation efforts fail within a year. ${ }^{2}$ Moreover, even though more than $70 \%$ of smokers report that they are interested in quitting, most continue smoking. ${ }^{3}$ One factor that may hinder smoking cessation is the presence of depression symptoms and anxiety. The positive reinforcing effects of nicotine may improve mood, cognition, and anxiety. Abstinence, in turn, may exacerbate these symptoms. Despite the higher prevalence of anxiety and depression in smokers, studies conducted with Brazilian populations have been unsuccessful to demonstrate the association between these symptoms and failure to stop smoking. ${ }^{4,5}$

In order for a smoker to quit, nicotine dependence needs to be counterbalanced by a high degree of motivation to stop smoking. Because smoking cessation may be a very difficult goal for those unable or unwilling to quit smoking, a reduction in cigarette consumption can be an initial step towards changing behavior and achieving complete abstinence..$^{6-8}$ Smoking reduction may increase the chance of future cessation because it reduces dependence, discontinues conditioning, and increases self-efficacy. ${ }^{8,9}$ Thus, reduced tobacco use signals that the smoker is motivated to change, and should therefore be considered a positive outcome. ${ }^{7}$

About two-thirds of the smokers trying to quit fail in the first week. This rate is similar for both treated ${ }^{10}$ and untreated smokers. ${ }^{2,11}$ The first days post-quit day seem to be the most difficult ones, because, in addition to learning a new behavior, smokers have to cope with withdrawal symptoms and cognitive and emotional difficulties. ${ }^{12}$ Notwithstanding, resisting smoking in the first moments after quitting is essential, as these symptoms tend to remain stable. ${ }^{13}$ Smokers who manage to remain abstinent and survive the first days without tobacco are more likely to succeed in the long term ${ }^{11,14}$ and less likely to have lapses or to relapse, ${ }^{10}$ probably because they feel encouraged and motivated. , $^{2,10}$ Conversely, it is very common, in the treatment setting, to have patients that stop attending therapeutic group activities or consultations because they have failed to quit smoking or have relapsed..$^{15}$

In view of the above, most attempts to quit smoking fail prematurely, and our understanding of this process remains inaccurate. In this sense, a better understanding of the behavioral changes taking place in the first days of a quit attempt is key to predicting early success and helping smokers who present more difficulties as early as possible. Moreover, achieving and maintaining tobacco abstinence may be compromised by biopsychosocial risk factors. ${ }^{16,17}$ Finally, the relationship between these changes and biochemical markers of exposure to tobacco, currently underestimated, may provide additional information on the changes taking place during the process of stopping or reducing smoking and determining abstinence or relapse.

Therefore, the objective of this study was to examine whether smokers attending a support group for smoking cessation and showing recent changes in their smoking behavior (quitting or reducing consumption) also show changes in measures such as intensity of nicotine dependence, motivational stage, and anxiety and depression symptoms, when compared to smokers that did not change their smoking habits.

\section{Methods}

\section{Procedures}

This short-term cohort study was conducted in a freeof-charge program for smoking cessation between July 2007 and November 2009. The program consisted of four weekly group meetings involving 8 to 12 participants and led by health professionals trained in cognitivebehavioral and motivational interviewing methods. Each session lasted for about 2 hours and was structured so as to provide information about the consequences of cigarette smoking, methods for quitting, stages of change, benefits of cessation, tobacco withdrawal symptoms, coping strategies, and relapse prevention. In each session, the participants received written materials structured according to the American Cancer Society ${ }^{18}$ and the Brazilian National Cancer Institute. ${ }^{19}$

At the beginning of the first session, participants were asked to sign an informed consent form. Subsequently, they answered a self-administered questionnaire covering sociodemographic characteristics, smoking history, nicotine dependence, motivational stages, and anxiety and depression symptoms. The second session focused on planning the quitting attempt and provided information on withdrawal signs and symptoms, risk situations, coping strategies, and relaxation exercises. In this session, the quit day for each participant was set. In the third session, difficulties faced during the attempt to stop smoking were approached, and strategies to maintain abstinence were reinforced. The last session focused on relapse prevention and reinforcement of skills and strategies for those who did not achieve abstinence. 
In the last session, participants filled out the same instruments used in the first session and were asked to inform whether they had stopped smoking, decreased tobacco use, or continued smoking the same amount of cigarettes. In addition to the questionnaires, urine samples were collected in the first and fourth sessions of the program and tested for cotinine. The Research Ethics Committee of Universidade Federal de Ciências da Saúde de Porto Alegre (UFCSPA) approved the study protocol (protocol no. 219/07).

\section{Subjects}

Participants were male and female smokers aged at least 18 years living in Porto Alegre, southern Brazil. Smokers were recruited from the community by newspaper and radio advertisements of a study comprising a support group for smoking cessation. By telephone, smokers received a description of how the group sessions would be conducted; participation in a group session was scheduled if the smoker chose to participate. Groups were offered at different times, including outside office hours, and participants could choose what time worked best. The individuals included were current cigarette smokers, or smokers who had stopped within the last week, and who showed up on the scheduled date. Smokers under 18 years of age or those who reported current illicit drug use, nicotine replacement therapy, bupropion treatment, presence of debilitating conditions that could interfere with group participation, as well as those who provided incomplete data on the questionnaires, preventing data analysis, were excluded from the sample.

A total of 183 smokers attended the first session. After application of our inclusion and exclusion criteria, 163 smokers were enrolled in the study. Only two smokers had quit smoking before starting the support group, and they were not more than 7 days abstinent. Only 54 smokers (33.1\%) completed the four sessions of the study. Figure 1 shows the patient selection process and dropout rates.

\section{Measures}

Nicotine dependence. The intensity of nicotine dependence was measured using the Fagerström Test for Nicotine Dependence (FTND), ${ }^{20,21}$ which comprises six questions related to smoking. Summing the results of all questions provided a total score ranging from 0 to 10 points, with higher scores indicating higher nicotine dependence.

Motivational stage. The motivational stage was measured by the University of Rhode Island Change Assessment Scale (URICA) ${ }^{22,23}$ and the Contemplation Ladder. ${ }^{24,25}$ URICA assesses the degree to which participants are willing to change their smoking behavior by asking whether they agree or disagree with certain presented statements. Responses are rated using a Likert scale. Based on the answers, one can evaluate scores for the stages of precontemplation, contemplation, action, and maintenance, as well as calculate a total score by adding the mean scores obtained for contemplation, action, and maintenance, and subtracting the mean score of the precontemplation subscale. The Contemplation Ladder, used in a brief form, presented five statements, and participants had to indicate the statement that best characterized their thinking in relation to smoking at the time. According to the statement chosen, a score raging from 0 to 10 was assigned to each response, with higher scores indicating higher motivation.

Anxiety symptoms. The Beck Anxiety Inventory (BAI) comprises 21 items describing various symptoms

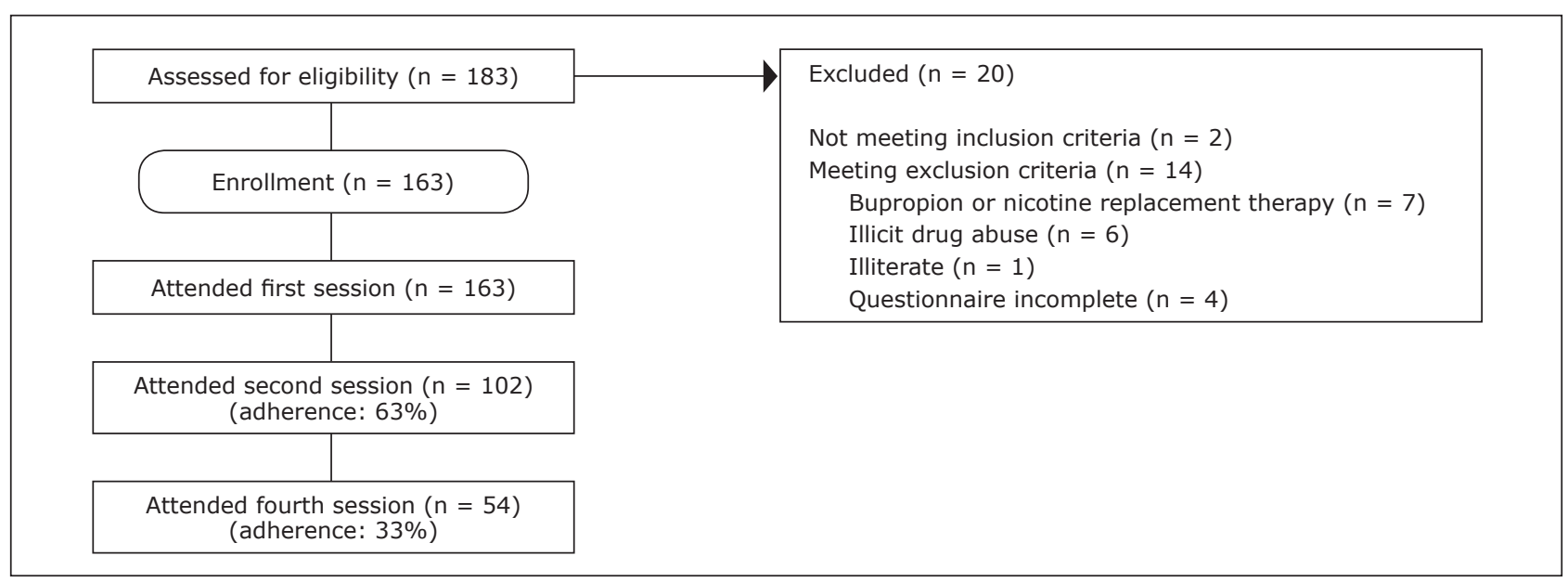

Figure 1 - Flowchart describing the selection of smokers and showing dropout rates in different sessions of the smoking cessation support group 
of anxiety. Subjects marked the level of intensity of each symptom using a range of 0 to 3 . The final score is obtained by summing all the items and matching that sum to a standardized severity level, as follows: minimum (0 to 11 points), mild (12 to 19 ), moderate (20 to 35 ), or severe (36 to 63 ). ${ }^{26,27}$

Depression symptoms. Symptoms of depression were assessed using the Beck Depression Inventory (BDI), a measure comprising 21 items and four response options for each item, ranging from 0 to 3, corresponding to increasing intensity of depression. The total score is obtained by summing individual scores and is used to classify between levels of depression, i.e., minimum ( 0 to 10 points), mild (11 to 19 ), moderate (20 to 30 ), or severe ( 31 to 63$).^{27,28}$

Smoking status. When filling out the questionnaire in the fourth session, smokers classified themselves as having quit, reduced tobacco intake, or maintained intake based on recent smoking habits. To confirm selfreported smoking status, cotinine urine concentration was assessed at the pharmacology laboratory of the Basic Health Sciences Department of UFCSPA using the colorimetric technique as described by Peach et al. ${ }^{29}$ This method was chosen because it shows good sensitivity and specificity in distinguishing between smokers and nonsmokers. Moreover, the method is sensitive to changes in smoking behavior, as it measures the concentrations of cotinine and other nicotine metabolites. ${ }^{30,31}$ Cotinine has a half-life of approximately 20 hours, ${ }^{32}$ and it derives solely from the metabolism of tobacco. ${ }^{33}$ Even though more specific and sensitive methods are available, they are also more expensive, time-consuming, and often unavailable in clinical biochemistry laboratories in developing countries. ${ }^{30}$

\section{Statistical analysis}

Baseline data were analyzed considering all enrolled smokers. Conversely, the analysis of changes in smoking behavior included only retained smokers, i.e., those who attended all four sessions of the support group.

For the analysis of retained smokers, groups were created based on self-reported smoking habits, confirmed by cotinine concentrations in urine samples. As a result, smokers were divided into two groups: 1) smokers who kept smoking (similar cotinine urinary concentrations in the first and fourth sessions); and 2) smokers who completely quit smoking, or at least reduced tobacco intake (confirmed by a $40 \%$ or greater reduction in cotinine concentrations from the first to the fourth session). Because an expressive reduction in smoking can cause changes in many biopsychosocial factors, it was deemed appropriate to combine quitters and reducers in the same group. Within each group, results were divided into baseline (first session) and final (fourth session) measures. The Kruskal-Wallis test or one-way analysis of variance (ANOVA) followed by Tukey's test were used to assess differences in the variables between our four resulting groups.

Association tests were performed using the chisquare test, and correlation tests were performed using Pearson's or Spearman's correlation coefficients. Missing data were excluded analysis by analysis. Statistical analyses were performed using the PASW Statistics version 18. Differences were considered significant when $p<0.05$.

\section{Results}

Table 1 shows the characteristics of the smokers included in the study, as well as characteristics of retained smokers, divided according to change in smoking habit reported and confirmed by urinary cotinine levels (smoking or abstinence/reduction) in the fourth week. The majority of enrolled smokers were female, married, with incomplete or complete high school (8 to 11 years of study), were employed or had some type of income. They also reported having one or more than one tobacco-related disease, being non-drinkers, and having attempted to quit smoking previously. These characteristics did not differ between retained or nonretained smokers (except for age) or between abstinent/ reduced smokers and non-quitting retained smokers. As usual, they started to smoke during adolescence. The level of depression was similar between non-retained and retained smokers (median $=12$ [8-21] and 10 [7-17], respectively; $p=0.116$ ), but anxiety levels were higher in non-retained smokers than in retained ones (median 13 [6-24] and 8 [4-13], respectively; $p=0.004$ ).

Intensity of nicotine dependence was positively correlated with baseline urinary cotinine concentrations $(r=0.364 ; p<0.001)$. Cotinine levels rose in association with responses indicating greater nicotine dependence on FTND. Four questions of the FTND were able to predict differences in the biochemical marker (Table 2); time to first cigarette and number of cigarettes per day were the ones that best predicted urinary cotinine concentration.

Testing at the fourth week of follow-up revealed a correlation between baseline urinary cotinine concentrations and the difference between final and baseline concentrations $(r=-0.555, p<0.001$, Figure 2$)$. The greatest changes in cotinine concentrations between the two tests were observed in smokers who had higher baseline concentrations.

Statistical analysis showed that only FTND and maintenance stage (URICA scale) scores differed after 
attendance of the four sessions of the smoking cessation program ( $p=0.001$ and $p<0.001$, respectively) (Table 3). Correlating these scores with differences in urinary cotinine concentrations revealed similar changes in both parameters, regardless of whether or not the smokers had changed their tobacco consumption habits (Figure 3 ).
The study also evaluated the authenticity of selfreported smoking status. Cotinine urinary concentrations showed that $61 \%(28 / 46)$ of the smokers reporting changes in their smoking habits had not actually reduced consumption, and that $25 \%(2 / 8)$ of the smokers denying changes showed a decrease in cotinine concentrations.

Table 1 - Demographic characteristics of the smokers included in the study, n (\%)

\begin{tabular}{|c|c|c|c|c|c|c|c|}
\hline & \multicolumn{4}{|c|}{ Enrolled smokers } & \multicolumn{3}{|c|}{ Retained smokers } \\
\hline & $\begin{array}{c}\text { Total* } \\
(\mathrm{n}=163)\end{array}$ & $\begin{array}{c}\text { Retained }^{+} \\
(n=54)\end{array}$ & $\begin{array}{c}\text { Non-retained }^{+} \\
(n=109)\end{array}$ & $\mathbf{p}$ & $\begin{array}{l}\text { Smoking }^{+} \\
(n=34)\end{array}$ & $\begin{array}{c}\text { Abstinence/ } \\
\text { reduction }^{+} \\
(\mathbf{n}=\mathbf{2 0})\end{array}$ & $\mathbf{p}$ \\
\hline \multicolumn{8}{|l|}{ Gender } \\
\hline Female & $105(64.4)$ & $35(33.3)$ & $70(66.7)$ & & $24(68.6)$ & $11(31.4)$ & \\
\hline Male & $58(35.6)$ & $19(32.8)$ & $39(67.2)$ & 1.000 & $10(56.6)$ & $9(47.4)$ & 0.376 \\
\hline \multicolumn{8}{|l|}{ Marital status } \\
\hline Single & $35(21.5)$ & $8(22.9)$ & $27(77.1)$ & & $5(62.5)$ & $3(37.5)$ & \\
\hline Married/living with a partner & $81(49.7)$ & $31(38.3)$ & $50(61.7)$ & & $19(61.3)$ & $12(39.7)$ & \\
\hline Divorced & $33(20.2)$ & $9(27.3)$ & $24(72.7)$ & & $6(66.7)$ & $3(33.3)$ & \\
\hline Widowed & $14(8.6)$ & $6(42.9)$ & $8(57.1)$ & 0.291 & $4(66.7)$ & $2(33.3)$ & 0.989 \\
\hline \multicolumn{8}{|l|}{ Education (4 missing) } \\
\hline$\leq 8$ years & $41(25.1)$ & $15(36.6)$ & $26(63.4)$ & & $9(60.0)$ & $6(40.0)$ & \\
\hline $8-11$ years & $62(38.0)$ & $17(27.4)$ & $45(72.6)$ & & $11(64.7)$ & $6(35.3)$ & \\
\hline$>11$ years & $46(28.2)$ & $18(39.1)$ & $28(61.9)$ & 0.633 & $12(66.7)$ & $6(32.3)$ & 0.762 \\
\hline \multicolumn{8}{|l|}{ Occupation (17 missing) } \\
\hline Paid work & $101(61.7)$ & $30(29.7)$ & $71(71.3)$ & & $16(53.3)$ & $14(47.7)$ & \\
\hline Pensioner & $20(12.7)$ & $9(45.0)$ & $11(55.0)$ & & $6(66.7)$ & $3(33.3)$ & \\
\hline Housewife & $16(9.8)$ & $5(31.3)$ & $11(68.8)$ & & $5(100.0)$ & $0(0.0)$ & \\
\hline Others & $9(5.5)$ & $2(22.2)$ & $7(77.8)$ & 0.544 & $2(100.0)$ & $0(0.0)$ & 0.175 \\
\hline Health conditions & $114(69.9)$ & $39(34.2)$ & $75(65.8)$ & 0.719 & $24(61.5)$ & $15(38.5)$ & 1.000 \\
\hline Drinking (3 missing) & $70(42.9)$ & $25(35.7)$ & $45(64.3)$ & 0.616 & $13(52.0)$ & $12(48.0)$ & 0.161 \\
\hline Quit attempt (3 missing) & $127(79.4)$ & $38(29.9)$ & $89(70.1)$ & 0.211 & $24(63.2)$ & $14(36.8)$ & 0.754 \\
\hline Age $($ mean $\pm S D)$ & $49.2 \pm 11.4$ & $47.6 \pm 12.2 \neq$ & $52.4 \pm 8.6$ & 0.004 & $53.7 \pm 9.1$ & $50.7 \pm 7.6$ & 0.226 \\
\hline
\end{tabular}

$\mathrm{SD}=$ standard deviation.

* Percentages refer to the column.

+ Percentages refer to the total value (row).

${ }^{\ddagger} p<0.01$.

Table 2 - Urinary cotinine concentrations divided according to FTND responses $(n=163)$

\section{FTND question}

1. How soon after you wake up do you smoke your first cigarette? ${ }^{+}$

2. Do you find it difficult to refrain from smoking in places where it is forbidden, etc.?*

3. Which cigarette would you hate most to give up?

4. How many cigarettes/day do you smoke? ${ }^{+}$

5. Do you smoke more frequently during the first hours after waking than during the rest of the day?

6. Do you smoke if you are so ill that you are in bed most of the day?*

FTND = Fagerström Test for Nicotine Dependence.

Cotinine concentrations expressed as mean \pm standard error of mean.

$* p<0.05$.

$+p<0.01$.

216 - Trends Psychiatry Psychother. 2013;35(3)

\section{Cotinine concentration}

Within 30 minutes: After 31 minutes or more:

$\begin{array}{ccc}16.5 \pm 1.1 \mu \mathrm{g} / \mathrm{mL} & 10.3 \pm 0.9 \mu \mathrm{g} / \mathrm{mL} & <0.001 \\ \text { Yes: } & \text { No: } & \\ 18.9 \pm 2.2 \mu \mathrm{g} / \mathrm{mL} & 12.9 \pm 0.8 \mu \mathrm{g} / \mathrm{mL} & 0.014\end{array}$

The first one in the morning: All others:

$14.7 \pm 1.1 \mu \mathrm{g} / \mathrm{mL} \quad 14.9 \pm 1.4 \mu \mathrm{g} / \mathrm{mL} \quad 0.907$

11 or more:

$15.6 \pm 1.0 \mu \mathrm{g} / \mathrm{mL}$

10 or less:

Yes:

$9.3 \pm 1.6 \mu \mathrm{g} / \mathrm{mL}$

0.009

No:

$15.5 \pm 1.1 \mu \mathrm{g} / \mathrm{mL}$

Yes:

$14.1 \pm 1.2 \mu \mathrm{g} / \mathrm{mL}$

0.412

No:

$15.9 \pm 1.1 \mu \mathrm{g} / \mathrm{mL}$

$12.0 \pm 1.4 \mu \mathrm{g} / \mathrm{mL}$

0.038 


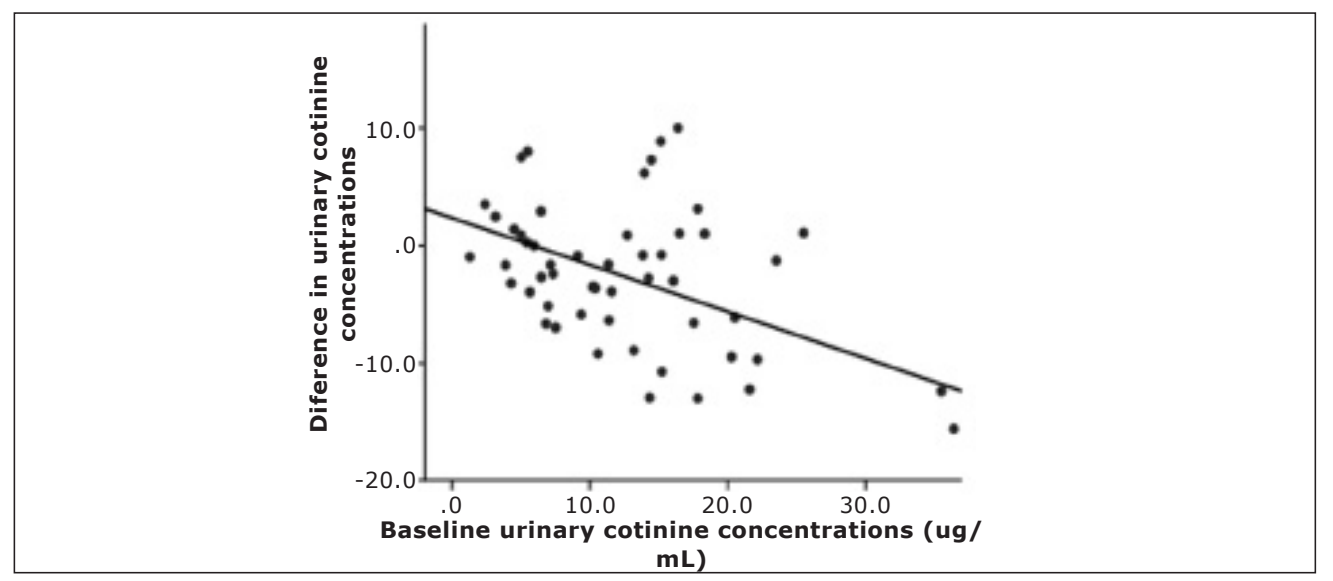

Figure 2 - Relationship between baseline urinary cotinine concentrations and the difference between final and baseline urinary cotinine concentrations in retained smokers $(n=54 ; r=-0.550, p<0.001)$

Table 3 - Scores obtained for nicotine dependence, motivation, and comorbidity scales in the different groups of smokers

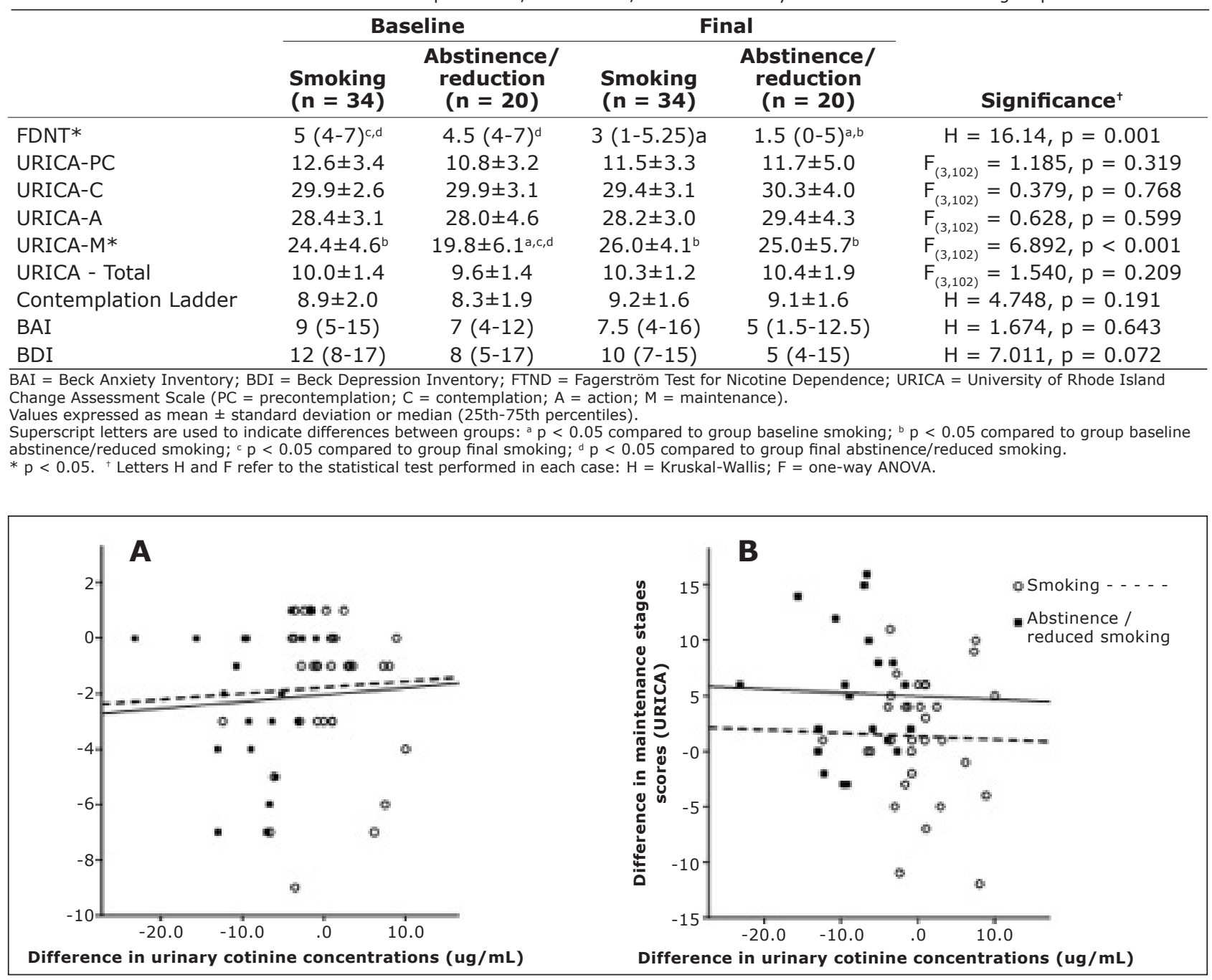

Figure 3 - Relationship between differences in urinary cotinine concentrations and A) differences in the intensity of nicotine dependence in smokers according their situation ( $n=54 ; r=0.041, p=0.82$ [smoking]; $r=0.052, p=0.827$ [abstinence/ reduction]); $B$ ) differences in maintenance stage scores in smokers according their situation $(n=54 ; r=-0.026, p=0.889$ [smoking]; $r=-0.028, p=0.906$ [abstinence/reduction]) 
The concordance of self-reported smoking status and urinary cotinine concentrations had a kappa index of 0.60 , indicating only moderate agreement $(p=0.445)$. As a result, only 24 of the 54 retained smokers were able to correctly identify their final smoking status. The comparison between smokers' self-reports and biochemical markers yielded an accuracy of $44 \%$ for self-report data.

\section{Discussion}

The first days of an attempt to quit smoking represent an important challenge for long-term abstinence. This study found that more than $60 \%$ of the smokers are unable to achieve their goal of changing tobacco consumption patterns, even when they had fully attended a smoking cessation program. Worst of all, only $12 \%$ of those who attended the first program meeting were able to effectively stop or reduce smoking, either because they did not attend the whole program or because they did not remain abstinent. Better news is that, for smokers who were able to at least reduce the amount of tobacco smoked daily, the intensity of nicotine dependence decreased and scores of motivational maintenance increased.

In the FTND scale, time to the first cigarette of the day and number of cigarettes smoked per day seemed to provide the best information for assessing intensity of nicotine dependence; data originating from these questions added appreciably to the prediction of biochemical levels of cotinine. In fact, some questionnaires use only these two questions to measure nicotine dependence, but the other questions contained in the FTND may serve to improve our understanding of smokers' behaviors. ${ }^{21}$ Nicotine dependence is frequently pointed out as a powerful predictor of the failure to achieve abstinence. Smokers who do not quit usually have higher levels of nicotine dependence. ${ }^{34-36}$ In the same way, smokers who reach cessation are supposedly those who are less nicotine dependent. Nevertheless, our results do not corroborate these statements.

Evidently, FTND scores decreased with the smokers' attempts to reduce or quit smoking, indicating that they had changed something in their behavior and had consequently reduced their physical dependence. Unexpectedly, however, the smokers who maintained their usual consumption (as confirmed biochemically) also showed a decrease in their FTND scores. We also observed many smokers who claimed reduction or cessation of the habit, however not confirmed by urinary cotinine levels. Smokers who engaged in the program to quit smoking initiated the process of change by demonstrating their desire to quit smoking; however, they had not yet changed their behavior. One may think that the smokers saw themselves changing their habit (i.e., feeling abstinent or less dependent on tobacco), but their behavior did not correspond to these expectations. Moreover, it is known that the dose of nicotine absorbed depends on the depth and frequency of puffs, and that smokers learn to titrate nicotine levels to manipulate plasma concentrations according to their needs. ${ }^{37}$ Thus, a slight decrease in the number of cigarettes smoked may not reflect a real decrease in nicotine exposure; this would explain the maintenance of urinary cotinine concentrations. Similar misclassification rates among self-reported tobacco users have been shown in different populations. ${ }^{38-41}$ The low accuracy of self-reported measures and the contradiction between such measures and biochemical measures underscore the great difficulty involved in quitting smoking, even when tobacco users are aware of the harmful effects of tobacco and of the need to change the habit. Finally, smokers may underreport smoking not to disappoint the health professional and to be socially accepted.

Even though cotinine tests are not $100 \%$ accurate, they serve well to indicate changes in tobacco exposure. The more prominent decrease in cotinine concentrations among smokers with higher baseline levels is an empirically logical result, as higher initial concentrations allow for greater reductions.

Data obtained with the URICA scale and the Contemplation Ladder showed that motivational scores remained stable regardless of whether the patient quit smoking. The exception to this was the maintenance stage of the URICA, whose scores increased for smokers who reduced or quit smoking. This increase demonstrates their commitment to remaining abstinent or smoking less. The association between advanced motivational stages and smoking reduction or cessation has been identified in previous studies, ${ }^{42,43}$ but not in our sample. Smokers who did not change their tobacco consumption presented higher baseline maintenance stage scores when compared to smokers who reduced tobacco consumption or quit, which suggests that even highly motivated smokers may not be fully ready to stop smoking. Similarly, Boardman et al. ${ }^{44}$ showed that smokers who did not manage to quit presented high levels of motivation and self-efficacy due to the hope of quitting in the next attempt.

In this study, anxiety symptoms did not show a relationship with the cessation/reduction process. Our result diverges from others found in the literature that report higher numbers of anxiety symptoms in more dependent smokers, especially women, and a decreased anxiety among individuals who remain abstinent. ${ }^{16,45}$ This could be related to limitations of the study, including the small sample size and the short period of analysis. Moreover, another study by our group found that higher anxiety levels were associated with a lower probability of the smoker keeping the treatment. ${ }^{46}$ Here it is important to consider that we included in this analysis only 
smokers who remained in the support group for 4 weeks, which may explain the lower anxiety levels observed. Zvolensky et al. ${ }^{47}$ pointed out that anxiety symptoms per se do not influence the chance of early smoking relapse, except in smokers with anxiety disorders.

Investigation of depression symptoms and other variables related to the treatment showed a lower intensity of depression among the smokers who joined the treatment vs. those smokers who did not join the program. This means that high levels of depression may hinder treatment adherence $^{48}$ and affect the process of smoking cessation in those who seek interventions to change their habit, heightening the probability of failure or relapse. ${ }^{49}$ Nicotine is known to act on neural circuits associated with affect regulation, ${ }^{50}$ and individuals will smoke to relieve feelings of sadness or negative affect, effectively using nicotine as a remedy for depression symptoms. ${ }^{51}$ As a result, quitting is more difficult for those who are depressed, who would have to learn a new skill to cope with sadness symptoms. Our results, however, did not uncover any differences among the groups in the periods analyzed, probably because the smokers who remained in treatment had low levels of depression symptoms to begin with.

Despite the recognized efficacy of group therapy for smoking cessation, adherence to group programs is a barrier to tobacco control; $23 \%$ of the participants leave treatment within the first month, and around $45 \%$ leave it within 2 months. ${ }^{48,52}$ In our study, adherence to the support group was even lower, with only $33.1 \%$ of the individuals attending all the meetings over 1 month. Poor adherence is also a problem in group treatment of other addictions; for example, only around $20 \%$ of alcoholics in Brazil continue attending Alcoholics Anonymous meetings after 6 months of follow-up. ${ }^{53}$ Comparing the approaches used here with studies conducted in other countries may be disappointing, mainly due to intrinsic characteristics of support groups in Brazil. Usually, recruitment is carried out reactively, and the participation of patients is not subject to any kind of incentive, especially financial ones.

The results of the present study should be considered with care. First, the small sample size, combined with the large number of dropouts, limits generalization of the findings. Also, we did not include a diagnostic assessment of past or present psychopathology or a more fine-grained analysis of the personal characteristics of patients, which may have interfered with smoking cessation. Also, the study included subjects who enrolled in a clinical setting, and therefore not be representative of all smokers.

Smoking cessation is a dynamic process. The early period of cessation typifies a moment of personal challenge, as behaving in a new way requires effort and not overcoming withdrawal signs and symptoms may preclude immediate success. This work showed that smokers who reduced or quit smoking, as well as those who did not change their habits, diminished the intensity of nicotine dependence, whereas only the ones who changed their habits raised their scores on the maintenance stage of the URICA scale. Whether the patients who did not reduce or quit tobacco smoking learned to report lower levels of dependence is a factor deserving further investigation. Greater knowledge about the motivation, dependence and comorbidity related to smoking will allow professionals to be better prepared to treat smokers, with more effective treatment plans and interference strategies tailored to these characteristics.

\section{References}

1. World Health Organization. WHO Report on the Global Tobacco Epidemic, 2008 - The MPOWER package. Geneva: WHO; 2008. http://www.who.int/tobacco/mpower/mpower_ report_full_2008.pdf.

2. Hughes JR, Keely J, Naud S. Shape of the relapse curve and long-term abstinence among untreated smokers. Addiction. 2004;99:29-38.

3. Carlini EA, Galduróz JC, Noto AR. II Levantamento domiciliar sobre o uso de drogas psicotrópicas no Brasil: estudo envolvendo as 108 maiores cidades do país - 2005. Brasília: Secretaria Nacional Antidrogas; 2007.

4. Azevedo RC, Fernandes RF. Factors relating to failure to quit smoking: a prospective cohort study. Sao Paulo Med J. 2011;129:380-6.

5. Lopes FL, Nascimento I, Zin WA, Valença AM, Mezzasalma MA, Figueira I, et al. Smoking and psychiatric disorders: a comorbidity survey. Braz J Med Biol Res. 2002;35:961-7.

6. Benowitz NL. Smoking less as a treatment goal for those who cannot stop smoking. Am J Med. 2004;116:203-5.

7. Peters EN, Hughes JR. The day-to-day process of stopping or reducing smoking: a prospective study of self-changers. Nicotine Tob Res. 2009;11:1083-92.

8. Stead LF, Lancaster T. Interventions to reduce harm from continued tobacco use. Cochrane Database Syst Rev. 2007;(3):CD005231.

9. Hughes JR, Carpenter MJ. Does smoking reduction increase future cessation and decrease disease risk? A qualitative review. Nicotine Tob Res. 2006;8:739-49.

10. Ferguson SG, Gitchell JG, Shiffman S, Sembower MA. Prediction of abstinence at 10 weeks based on smoking status at 2 weeks during a quit attempt: secondary analysis of two parallel, 10-week, randomized, double-blind, placebocontrolled clinical trials of $21-\mathrm{mg}$ nicotine patch in adult smokers. Clin Ther. 2009;31:1957-65.

11. Powell J, Dawkins L, West R, Powell J, Pickering A. Relapse to smoking during unaided cessation: clinical, cognitive and motivational predictors. Psychopharmacology (Berl). 2010;212(4):537-49.

12. Weinberger AH, McKee SA, George TP. Changes in smoking expectancies in abstinent, reducing, and non-abstinent participants during a pharmacological trial for smoking cessation. Nicotine Tob Res. 2010;12:937-43.

13. Tomson T, Toftgard M, Gilljam H, Helgason AR. Symptoms in smokers trying to quit. Tob Induc Dis. 2006;3:44-58.

14. Herd N, Borland R, Hyland A. Predictors of smoking relapse by duration of abstinence: findings from the International Tobacco Control (ITC) Four Country Survey. Addiction. 2009;104:2088-99. 
15. Aguiar M, Todo-Bom F, Felizardo M, Macedo R, Caeiro F, Sotto-Mayor R, et al. Four years' follow up at a smoking cessation clinic. Rev Port Pneumol. 2009;15:179-97.

16. McClave AK, Dube SR, Strine TW, Kroenke K, Caraballo RS, Mokdad AH. Associations between smoking cessation and anxiety and depression among U.S. adults. Addict Behav. 2009;34:491-7.

17. Mykletun A, Overland S, Aaro LE, Liabo HM, Stewart R. Smoking in relation to anxiety and depression: evidence from a large population survey: the HUNT study. Eur Psychiatry. 2008;23:77-84.

18. American Cancer Society. Freshstart. Georgia: ACS; 1996.

19. Brasil, Ministério da Saúde. Ajudando seu paciente a deixar de fumar. Rio de Janeiro: Instituto Nacional do Câncer; 1997.

20. Carmo JT, Pueyo AA. A adaptação do português do Fagerström Test for Nicotine Dependence (FTND) para avaliar a dependência e tolerância à nicotina em fumantes brasileiros. Rev Bras Med. 2002;58:73-80.

21. Heatherton TF, Kozlowski LT, Frecker RC, Fagerström KO. The Fagerström Test for Nicotine Dependence: a revision of the Fagerström Tolerance Questionnaire. $\mathrm{Br}$ J Addict. 1991;86:1119-27.

22. Figlie NB. Metodologia de pesquisa em dependência química. In: XIV Congresso Brasileira de Alcoolismo, Tabagismo e Outras Dependências; Gramado, Brazil; 2001.

23. McConnaughy EA, Prochaska JO, Velicer WF. Stages of change in psychotherapy: measurement and sample profiles. Psychother Theory Res Pract. 1983;20:368-75.

24. Biener $L$, Abrams DB. The Contemplation Ladder: validation of a measure of readiness to consider smoking cessation. Health Psychol. 1991;10:360-5.

25. Terra MB, da Silveira DX, Moreira TC, Ferigolo M, Mazoni $C$, Arena FX, et al. Convergent validation study of the Contemplation Ladder for application via telephone in tobacco users. J Bras Psiquiatr. 2009;58:143-9.

26. Beck AT, Epstein N, Brown G, Steer RA. An inventory for measuring clinical anxiety: psychometric properties. J Consult Clin Psychol. 1988;56:893-7.

27. Cunha JA. Manual da versão em português das escalas Beck. São Paulo: Casa do Psicólogo; 2001.

28. Beck AT, Ward CH, Mendelson M, Mock J, Erbaugh J. An inventory for measuring depression. Arch Gen Psychiatry. 1961;4:561-71.

29. Peach H, Ellard GA, Jenner PJ, Morris RW. A simple, inexpensive urine test of smoking. Thorax. 1985;40:351-7.

30. Okayama A, Sato T. Assessment of smoking status among workers using an improved colorimetric method. Ind Health. 2004;42:348-51.

31. Smith RF, Mather HM, Ellard GA. Assessment of simple colorimetric procedures to determine smoking status of diabetic subjects. Clin Chem. 1998;44:275-80.

32. Taylor P. Agents acting at the neuromuscular junction and autonomic ganglia. In: Brunton LL, Lazo JS, Parker KL, editors. Goodman and Gilman's the pharmacological basis of therapeutics. 11th ed. New York: McGraw-Hill; 2006.

33. Cope G, Nayyar P, Holder R, Gibbons J, Bunce R. A simple near-patient test for nicotine and its metabolites in urine to assess smoking habit. Clin Chim Acta. 1996;256:135-49.

34. Asfar T, Weg MV, Maziak W, Hammal F, Eissenberg T, Ward KD. Outcomes and adherence in Syria's first smoking cessation trial. Am J Health Behav. 2008;32:146-56.

35. Chatkin JM, Mariante de Abreu C, Haggsträm FM, Wagner $M B$, Fritscher CC. Abstinence rates and predictors of outcome for smoking cessation: do Brazilian smokers need special strategies? Addiction. 2004;99:778-84.

36. Hagimoto A, Nakamura M, Morita T, Masui S, Oshima A. Smoking cessation patterns and predictors of quitting smoking among the Japanese general population: a 1-year follow-up study. Addiction. 2010;105:164-73.
37. Hukkanen J, Jacob P, Benowitz NL. Metabolism and disposition kinetics of nicotine. Pharmacol Rev. 2005;57:79-115.

38. Balhara $Y P$, Jain $R$, Sundar AS, Sagar R. Use of cotinine urinalysis to verify self-reported tobacco use among male psychiatric out-patients. Lung India. 2012;29:217-20.

39. Connor Gorber S, Schofield-Hurwitz S, Hardt J, Levasseur G, Tremblay M. The accuracy of self-reported smoking: a systematic review of the relationship between self-reported and cotinine-assessed smoking status. Nicotine Tob Res. 2009; 11:12-24.

40. Noonan D, Jiang Y, Duffy SA. Utility of biochemical verification of tobacco cessation in the Department of Veterans Affairs. Addict Behav. 2013;38:1792-5.

41. Pérez-Stable EJ, Marín G, Marín BV, Benowitz NL. Misclassification of smoking status by self-reported cigarette consumption. Am Rev Respir Dis. 1992;145:53-7.

42. Helgason AR, Tomson T, Lund KE, Galanti R, Ahnve S, Gilljam $\mathrm{H}$. Factors related to abstinence in a telephone helpline for smoking cessation. Eur J Public Health. 2004;14:306-10.

43. Peters EN, Hughes JR, Callas PW, Solomon LJ. Goals indicate motivation to quit smoking. Addiction. 2007;102:1158-63.

44. Boardman T, Catley D, Mayo MS, Ahluwalia JS. Self-efficacy and motivation to quit during participation in a smoking cessation program. Int J Behav Med. 2005;12:266-72.

45. Nerín I, Beamonte A, Gargallo P, Jiménez-Muro A, Marqueta A. Ganancia ponderal al dejar de fumar y su relación con la ansiedad. Arch Bronconeumol. 2007;43:9-15.

46. Figueiró LR. Características de fumantes associadas à adesão ao tratamento e à mudança de comportamento [dissertação]. Porto Alegre: Universidade Federal de Ciências da Saúde de Porto Alegre; 2010.

47. Zvolensky MJ, Stewart SH, Vujanovic AA, Gavric D, Steeves D. Anxiety sensitivity and anxiety and depressive symptoms in the prediction of early smoking lapse and relapse during smoking cessation treatment. Nicotine Tob Res. 2009; 11:323-31.

48. Curtin L, Brown RA, Sales SD. Determinants of attrition from cessation treatment in smokers with a history of major depressive disorder. Psychol Addict Behav. 2000;14:134-42.

49. Glassman AH, Covey LS, Stetner F, Rivelli S. Smoking cessation and the course of major depression: a follow-up study. Lancet. 2001;357:1929-32.

50. Picciotto MR. Common aspects of the action of nicotine and other drugs of abuse. Drug Alcohol Depend. 1998;51:165-72.

51. Park ER, Chang Y, Quinn V, Regan S, Cohen L, Viguera A, et al. The association of depressive, anxiety, and stress symptoms and postpartum relapse to smoking: a longitudinal study. Nicotine Tob Res. 2009;11:707-14.

52. Camarelles F, Asensio A, Jiménez-Ruiz C, Becerril B, Rodero D, Vidaller O. Efectividad de la intervención grupal para la deshabituación tabáquica. Ensayo clínico aleatorizado. Med Clin (Barc). 2002; 119:53-7.

53. Terra MB, Barros HM, Stein AT, Figueira I, Palermo LH, Athayde LD, et al. Do alcoholics anonymous groups really work? Factors of adherence in a Brazilian sample of hospitalized alcohol dependents. Am J Addict. 2008;17:48-53.

\section{Correspondence}

Luciana Rizzieri Figueiró

VivaVoz - Universidade Federal de Ciências da Saúde de Porto Alegre (UFCSPA)

Rua Sarmento Leite, 245, sala 316, Centro

90050-170 - Porto Alegre, RS - Brazil

Tel./Fax: +55 (51) 3303.8764

E-mail: rizzieri@ufcspa.edu.br 